\title{
A Case of Extrapyramidal Symptoms Secondary to Long-Acting Injectable Paliperidone Palmitate
}

\author{
Samer El Hayek, Bernadette Mdawar and Farid Talih* \\ Department of Psychiatry, American University of Beirut, Lebanon
}

*Corresponding author: Farid Talih, Associate Professor of Clinical Psychiatry, Department of Psychiatry, Faculty of Medicine, American University of Beirut, Beirut, Lebanon.

Received Date: November 20, 2019

Published Date: December 04, 2019

\begin{abstract}
Paliperidone palmitate is a long-acting injectable formulation of the atypical antipsychotic paliperidone. The once-monthly injection is approved for acute and maintenance therapy of schizophrenia in adults. Extrapyramidal symptoms are a known adverse effect of antipsychotics; incidence rates of EPS with PP are up to 18\%. Given its longer half-life and steady blood levels, PP-induced EPS can cause a sustained and serious functional impairment of several months' duration, significantly impacting the quality of life. We report a case of severe combined EPS following the first injection of PP. Rapid improvement of symptoms occurred after providing a combination of diphenhydramine, trihexyphenidyl, diazepam, and carbidopa/levodopa.
\end{abstract}

Keywords: Paliperidone palmitate; Long-acting injectable; Side effects; Extrapyramidal symptoms; Carbidopa/levodopa

Abbreviations: PP: Paliperidone Palmitate; EPS: Extrapyramidal Symptoms; LAI: Long-Acting Injectable; NMS: Neuroleptic Malignant Syndrome; SAS: Simpson-Angus EPS Scale; ESRS: Extrapyramidal Symptom Rating Scale; XR: Extended Release; IM: Intramuscular

\section{Introduction}

Paliperidone palmitate (PP) is a long-acting injectable (LAI) formulation of the atypical antipsychotic paliperidone. It mainly functions as central D2 dopamine and 5-HT2A serotonin receptors antagonist. It also antagonizes alpha-1 and alpha-2 adrenergic and $\mathrm{H} 1$ histaminergic receptors. Peak plasma level is achieved 13 to 17 days after receiving the injection, and the median half-life of each injection ranges between 25 and 49 days. The recommended initiation schedule employs a dose of $150 \mathrm{mg}$ (the highest approved dose) on day 1 , followed by $100 \mathrm{mg}$ on day 8 , then a monthly maintenance dose of $75 \mathrm{mg}$ (recommended range of 25-150 $\mathrm{mg}$ ) [1]. Of the various side effects of PP, the incidence rate of extrapyramidal symptoms (EPS) reaches 18\% [2].

In this report, we present a case study of a patient treated with PP injection, followed by an occurrence of severe acute dystonia, akathisia, and Parkinsonism. To our knowledge, this is the first published case report of severe combined EPS secondary to PP. Informed consent was obtained prior to the writing of the manuscript.

\section{Case Presentation}

$\mathrm{M}$ is a 31-year-old male with a previous diagnosis of bipolar disorder type I, multiple past hospitalizations for manic and depressive episodes, and a documented history of risperidoneinduced acute dystonia. In 2018, M presented to the emergency department of our institution for generalized body stiffness, dysphagia, and hypersalivation of four days duration. These symptoms started a few hours following intramuscular injection of PP (150 mg).

Two weeks before presentation, the patient was admitted to another institution for a suicidal attempt in the setting of a mixed mood episode. There, he was started on oral paliperidone for three days without documented adverse effects. He then received the loading dose of PP injection and was discharged, on the same day. M was also receiving the following additional medications: clozapine (50 mg daily), lithium, bupropion, and biperiden. Clozapine was started during the admission, concomitantly with paliperidone. The clinical decision behind its use was not documented. The 
rationale behind the prescription of biperiden, an anticholinergic medication, was also not mentioned. We postulate that prior physicians provided it was for prophylactic purposes in light of the patient's previous history of risperidone-induced EPS.

Few hours after taking the injection and returning home, the patient initially sustained a bilateral upper extremity tremor. Symptoms gradually evolved into diffuse stiffness, an inner feeling of restlessness (akathisia), and dysphagia with decreased oral intake. The patient also experienced bradykinesia, painful posturing, and frequent muscle cramps, culminating into gait instability and insomnia secondary to back stiffness/pain. He received an intramuscular injection of diphenhydramine $25 \mathrm{mg}$ and an oral tab of trihexyphenidyl $2.5 \mathrm{mg}$ two days before presentation, with no improvement in symptoms.

Upon presentation to our emergency department, M was conscious and fully oriented. He was in a seated position, with his back arched. He had a masked facial expression with a fixed nonreactive affect and described a sense of inner restlessness. On neurological exam, the patient had a slurred speech and was excessively salivating. He displayed diffused upper and lower extremity cogwheel rigidity, with an incapacity to perform shoulder elevation or lateral head tilting. The patient also demonstrated bilateral lower extremity clonus and overall hyporeflexia. His gait was bradykinetic and unstable. He was tachycardic and tachypneic. No other abnormalities were detected on the remainder of the full physical examination.

The differential diagnosis upon presentation included druginduced EPS, neuroleptic malignant syndrome (NMS), and catatonia. To rule out NMS, the emergency team conducted a laboratory workup that came back unrevealing (normal white count and serum creatine kinase). The lithium level was within the therapeutic range; creatinine, electrolytes, liver function tests, thyroid function tests, and the electrocardiogram were also normal. On objective testing, the patient scored 28/40 on the Simpson-Angus EPS scale (SAS) and 51/102 (examination of parkinsonism and akathisia subscale) and 32/60 (examination of dystonia subscale) on the Extrapyramidal Symptom Rating Scale (ESRS). Taking into consideration the clinical presentation, history, laboratory findings, and scales' results, $\mathrm{M}$ subsequently received a diagnosis of acute dystonia, parkinsonism, and akathisia secondary to PP injection.

In the emergency department, the patient was given an intravenous load of diphenhydramine $(50 \mathrm{mg})$ with limited improvement in speech and then admitted to the neurology intensive care unit. He was started on intravenous diphenhydramine (25 mg three times daily), carbidopa/levodopa (25/100 mg half tab orally four times daily), and trihexyphenidyl ( $5 \mathrm{mg}$ orally twice daily). Within 24 hours, intravenous diazepam (2.5 mg twice daily) was also added. The clinical course during the hospital stay was uncomplicated, without evidence of hemodynamic instability. The dystonic reaction started to resolve gradually after 72 hours.
The patient received daily physical therapy, had decreased sialorrhea, and was slowly able to tolerate oral intake. Follow-up on scores of objective scales scores three days after treatment initiation was 12/40 (SAS), 28/102 (ESRS - examination of parkinsonism and akathisia subscale), and 24/60 (ESRS - examination of dystonia subscale). One-month follow-up in the clinic showed mild upper extremities tremor and residual bradykinesia. The psychiatrist had maintained $\mathrm{M}$ on the same dosages of carbidopa/levodopa and trihexyphenidyl, along with the previously prescribed Lithium, while discontinuing all other medications and antipsychotics. The patient was subsequently lost to follow-up, most likely due to the fact that he lives in a remote area quite far from our medical center.

\section{Discussion}

In general, the odds of EPS are quite similar between oral antipsychotics and depot formulation [8]. On the contrary, when it comes to PP, differences exist between oral medication and the LAI. The injectable form seems to be safer than oral paliperidone, given that it has lower rates of spontaneously reported EPS, lower rates of antiparkinsonian medications use, and a more considerable improvement on EPS scales [2]. Nevertheless, EPS remain a common treatment-emergent adverse effect in patients receiving PP regardless of the injection's dosage, reaching an incidence of $8.5 \%$ in various open-label studies $[9,10]$. In a very recent 18-months cohort study, $31.3 \%$ of patients receiving the LAI PP developed EPS, akathisia (13.4\%) and parkinsonism (16\%) being the most common [11].

Results from a pooled analysis of seven randomized controlled trials showed that spontaneously reported EPS started as soon as the first week of PP treatment, whether in oral or LAI form [2] Although serum level progressively decreases to its therapeuticlevel in around a month of the injection, the drug can stay in circulation for additional few months given its long half-life of 25 to 50 days [12]. As a result, if EPS occur, it may be challenging to manage them as they can last for a prolonged period even after discontinuing the medication, thus possibly explaining the persistent residual symptoms in our patient during his clinic follow-up. Our patient also had two major risk factors for EPS: a history of risperidoneinduced acute dystonia and a diagnosis of an affective disorder [13]. Other elements that possibly accounted for the severity of his condition include the short duration of assessment of tolerance to oral PP, the receipt of the highest approved dose of PP LAI, and immediate discharge after receiving the injection.

Many treatment options are available for different types of EPS. While anticholinergics, in both oral and parenteral forms, are commonly used as a first-line treatment in acute dystonia [14], data about their use in akathisia is ambiguous [15], and their evidence in parkinsonism is only supported by expert opinion [16]. Other available treatment options include intravenous diazepam for the management of acute dystonia and akathisia [17] and propranolol as a first choice in akathisia [18]. For drug-induced parkinsonism, prevention remains the primary strategy of management. Switching to an antipsychotic with a lesser risk of EPS, such as quetiapine or 
clozapine, is possible if antipsychotic treatment is still needed or if drug-induced parkinsonism is sustained for a longer duration [19].

In concordance with the reported evidence and the previously reported cases (Table 1), we used anticholinergic agents and benzodiazepines, in addition to carbidopa/levodopa for the treatment of our patient. Previous studies assessing the use of dopaminergic therapy, including levodopa, in EPS have so far shown inconsistent results with differing responses between dystonia and parkinsonism. Indeed, levodopa was previously described as ineffective in treating drug-induced parkinsonism [20]. However, it might exert a beneficial effect when parkinsonism co-exists with dystonia [21]. Nonetheless, some physicians raised concerns about its associated risk of psychosis [16]. Although we used carbidopa/ levodopa as part of the management of our case, given the severity of the patient's presentation, the observed improvement cannot be explained solely by its use. Recovery could be due to either the use of the commonly prescribed medications, carbidopa/ levodopa, or their combination.

Table 1: Summary of published case reports of extrapyramidal symptoms induced by long-acting injectable Paliperidone Palmitate.

\begin{tabular}{|c|c|c|c|c|c|c|c|}
\hline Study & $\begin{array}{l}\text { Age } \\
\text { Gender }\end{array}$ & Diagnosis & Medication & Type of EPS & $\begin{array}{l}\text { Onset of } \\
\text { EPS }\end{array}$ & $\begin{array}{l}\text { Duration } \\
\text { of EPS }\end{array}$ & Treatment (/day) \\
\hline $\begin{array}{l}\text { Jang and } \\
\text { Woo [3] }\end{array}$ & $\begin{array}{c}53 \\
\text { Female }\end{array}$ & Schizophrenia & PP 150mg & $\begin{array}{c}\text { Tremor Rigidity Gait } \\
\text { instability }\end{array}$ & $\begin{array}{l}7 \text { days after } \\
\text { 1st injection }\end{array}$ & 5 months & $\begin{array}{l}\text { Clozapine } 150 \mathrm{mg} \\
\text { Procyclidine } 10 \mathrm{mg} \\
\text { Propranolol } 40 \mathrm{mg} \\
\text { Lorazepam } 2 \mathrm{mg} \\
\text { Flunitrazepam 1mg }\end{array}$ \\
\hline $\begin{array}{l}\text { Marques } \\
\quad[4]\end{array}$ & $\begin{array}{c}64 \\
\text { Female }\end{array}$ & $\begin{array}{l}\text { Schizo- } \\
\text { affective } \\
\text { Disorder }\end{array}$ & $\begin{array}{c}\text { Paliperidone XR } 12 \mathrm{mg} \text { PP } \\
\text { LAI 150mg }\end{array}$ & $\begin{array}{l}\text { Blepharospasm Dystonia } \\
\text { (oro-mandibular) }\end{array}$ & $\begin{array}{l}1 \text { month } \\
\text { after } 1 \mathrm{st} \\
\text { injection }\end{array}$ & 6 months & Clozapine $100 \mathrm{mg}$ \\
\hline $\begin{array}{l}\text { Singh et } \\
\text { al. [7] }\end{array}$ & 22 Male & $\begin{array}{l}\text { Unspecified } \\
\text { nonorganic } \\
\text { psychosis }\end{array}$ & $\begin{array}{l}\text { Olanzapine Paliperidone } \\
\text { ( } 3-6 \mathrm{mg} \text { ) in parallel to } \\
\text { LAI PP LAI 150mg, then } \\
\text { monthly PP LAI 75mg }\end{array}$ & $\begin{array}{l}\text { Progressively worsening } \\
\text { tardive dystonia/ } \\
\text { dyskinesia (of facial, } \\
\text { upper extremities, } \\
\text { cranial, and cervical } \\
\text { trunk muscles, torticollis, } \\
\text { and opisthotonos) } \\
\text { Choreoathetoid } \\
\text { movements }\end{array}$ & $\begin{array}{l}1.5 \text { years } \\
\text { after PP LAI }\end{array}$ & 3 months & $\begin{array}{c}\text { Clozapine } 400 \mathrm{mg} \\
\text { Clonazepam 6mg } \\
\text { Tetrabenazine } 75 \mathrm{mg} \\
\text { Baclofen 60mg } \\
\text { Trihexyphenidyl } 2 \mathrm{mg}\end{array}$ \\
\hline $\begin{array}{l}\text { Ma et al. } \\
{[6]}\end{array}$ & $\begin{array}{c}28 \\
\text { Female }\end{array}$ & Schizophrenia & $\begin{array}{l}\text { PP LAI 150mg, PP LAI } \\
\text { 100mg after } 1 \text { week, PP } \\
\text { LAI } 150 \mathrm{mg} \text { for } 5 \text { months, } \\
\text { then PP LAI } 100 \text { mg for } 6 \\
\text { months }\end{array}$ & $\begin{array}{l}\text { Progressively worsen- } \\
\text { ing tardive dystonia } \\
\text { (dysphagia to liquids, } \\
\text { jaw tightness, restricted } \\
\text { mouth opening, tongue } \\
\text { clumsiness, and severe } \\
\text { dysarthria) }\end{array}$ & $\begin{array}{l}10 \text { months } \\
\text { after PP LAI }\end{array}$ & 5 months & $\begin{array}{l}\text { Clozapine } 75 \mathrm{mg} \\
\text { Clonazepam } \\
\text { Amantadine Baclofen }\end{array}$ \\
\hline $\begin{array}{l}\text { Ustohal et } \\
\text { al. [5] }\end{array}$ & 22 Male & $\begin{array}{c}\text { Paranoid } \\
\text { Schizophrenia }\end{array}$ & $\begin{array}{l}\text { Risperdal 4mg Risperdal } \\
\text { LAI 37.5mg PP LAI 75mg }\end{array}$ & $\begin{array}{c}\text { Dystonia (orofacial/ } \\
\text { neck muscles) Akathisia } \\
\text { Breathing problems }\end{array}$ & $\begin{array}{l}\text { Few hours } \\
\text { after 5th } \\
\text { injection }\end{array}$ & 15 days & $\begin{array}{c}\text { Diazepam (10mg IM } \\
\text { once) Biperiden (2mg/ } \\
\text { day for } 2 \text { doses then } \\
4 \mathrm{mg} / \text { day) Clonazepam } \\
2 \mathrm{mg}\end{array}$ \\
\hline
\end{tabular}

\section{Conclusion}

To our knowledge, this is the first case report of severe EPS following the first injection of PP in a patient with an affective disorder, with improvement of symptoms after providing a combination of diphenhydramine, trihexyphenidyl, diazepam, and carbidopa/levodopa. In the context of using LAIs, psychiatrists should keep in mind EPS risk factors and avoid combining antipsychotics. Establishing oral tolerability for an appropriate duration of commonly one week is required. Opting to initiate a dose less than the maximal approved dosage of the LAI (in light of a previous history of EPS) and closely monitoring the patient after providing the injection maybe a reasonable strategy to prevent serious adverse effects. In severe EPS, admission to the intensive care unit and considering multiple pharmacological interventions for treatment, including carbidopa/levodopa and clozapine, should be considered.

\section{Acknowledgement}

None.

\section{Conflict of Interest}

No conflict of interest.

\section{References}

1. (2009) NVEGA SUSTENNA® (paliperidone palmitate) extended-release injectable suspension, for intramuscular use. NJ Janssen Pharmaceutical Companies.

2. Gopal S, Liu Y, Alphs L, Savitz A, Nuamah I, et al. (2013) Incidence and time course of extrapyramidal symptoms with oral and long-acting injectable paliperidone: a posthoc pooled analysis of seven randomized controlled studies. Neuropsychiatr Dis Treat 9: 1381-1392.

3. Jang S, Woo J (2017) Five Month-Persistent Extrapyramidal Symptoms following a Single Injection of Paliperidone Palmitate: A Case Report. Clin Psychopharmacol Neurosci 15(3): 288-291.

4. Marques JG (2017) Oral Facial Dystonia (Meige or Brueghel Syndrome) Induced by Paliperidone Palmitate. Prim Care Companion CNS Disord 19(1). 
5. Ustohal L, Prikryl R, Hublova V, Mayerova M, Kucerova HP, et al (2014) Severe acute dystonia/akathisia after paliperidone palmitate application--a case study. Int J Neuropsychopharmacol 17(2): 341-342.

6. Ma CH, Chien YL, Liu CC, Chen IM, Lin CH (2016) A case of tardive dystonia associated with long-acting injectable paliperidone palmitate. Eur Neuropsychopharmacol 26(7): 1251-1252.

7. Singh S, Gupta A, Kuppili PP, Pattanayak RD, Khandelwal SK (2016) Paliperidone Palmitate-Associated Severe Refractory Tardive Dyskinesia With Tardive Dystonia: Management and Six-Months Follow-Up. J Clin Psychopharmacol 36(4): 391-393.

8. Schillevoort I, Herings RM, Hugenholtz GW, De Boer A, Nolen WA, et al. (2005) Antipsychotic-induced extrapyramidal syndromes in psychiatric practice: a case-control study. Pharm World Sci 27(4): 285-289.

9. Si T, Zhang K, Tang J, Fang M, Li K, et al. (2015) Efficacy and safety of flexibly dosed paliperidone palmitate in Chinese patients with acute schizophrenia: an open-label, single-arm, prospective, interventional study. Neuropsychiatr Dis Treat 11: 1483-1492.

10. Fu DJ, Turkoz I, Simonson RB, Walling D, Schooler N, et al. Paliperidone Palmitate Once-Monthly Injectable Treatment for Acute Exacerbations of Schizoaffective Disorder. J Clin Psychopharmacol 36(4): 372-376.

11. Zhang F, Si T, Chiou CF, Harris AW, Kim CY, et al. (2015) Efficacy, safety, and impact on hospitalizations of paliperidone palmitate in recent-onset schizophrenia. Neuropsychiatr Dis Treat 11: 657-668.

12. Owen RT (2010) Paliperidone palmitate injection: Its efficacy, safety and tolerability in schizophrenia. Drugs Today (Barc) 46(7): 463-471.

13. Gao K, Kemp DE, Ganocy SJ, Gajwani P, Xia G, et al. (2008) Antipsychoticinduced extrapyramidal side effects in bipolar disorder and schizophrenia: a systematic review. J Clin Psychopharmacol 28(2): 203209.

14. Harten PN, Hoek HW, Kahn RS (1999) Acute dystonia induced by drug treatment. BMJ 319(7210): 623-626.

15. Braude WM, Barnes TR, Gore SM (1983) Clinical characteristics of akathisia. A systematic investigation of acute psychiatric inpatient admissions. Br J Psychiatry 143: 139-150.

16. Avorn J, Bohn RL, Mogun H, Gurwitz JH, Monane M, et al. (1995) Neuroleptic drug exposure and treatment of parkinsonism in the elderly: a case-control study. Am J Med 99(1): 48-54.

17. Gagrat D, Hamilton J, Belmaker RH (1978) Intravenous diazepam in the treatment of neuroleptic-induced acute dystonia and akathisia. Am J Psychiatry 135(10): 1232-1233.

18. Lipinski JF, Zubenko GS, Cohen BM, Barreira PJ (1984) Propranolol in the treatment of neuroleptic-induced akathisia. Am J Psychiatry 141(3): 412-415.

19. Dayalu P, Chou KL (2008) Antipsychotic-induced extrapyramidal symptoms and their management. Expert Opinion on Pharmacotherapy 9(9): 1451-1462.

20. Hardie RJ, Lees AJ (1988) Neuroleptic-induced Parkinson's syndrome: clinical features and results of treatment with levodopa. J Neurol Neurosurg Psychiatry 51(6): 850-854.

21. Termsarasab P, Yang AC, Frucht SJ (2015) Intermediate Phenotypes of ATP1A3 Mutations: Phenotype-Genotype Correlations. Tremor Other Hyperkinet Mov (N Y) 5: 336. 